\title{
TITLE:
}

\section{Capacitance spectroscopy study of deep levels in Cl-implanted 4H-SiC}

$\operatorname{AUTHOR}(S)$ :

Alfieri, G.; Kimoto, T.

\section{CITATION:}

Alfieri, G....[et al]. Capacitance spectroscopy study of deep levels in Climplanted 4H-SiC. Journal of Applied Physics 2012, 112(6): 063717.

\section{ISSUE DATE:}

2012-09-27

URL:

http://hdl.handle.net/2433/187957

\section{RIGHT:}

(c) 2012 American Institute of Physics. This article may be downloaded for personal use only. Any other use requires prior permission of the author and the American Institute of Physics. 


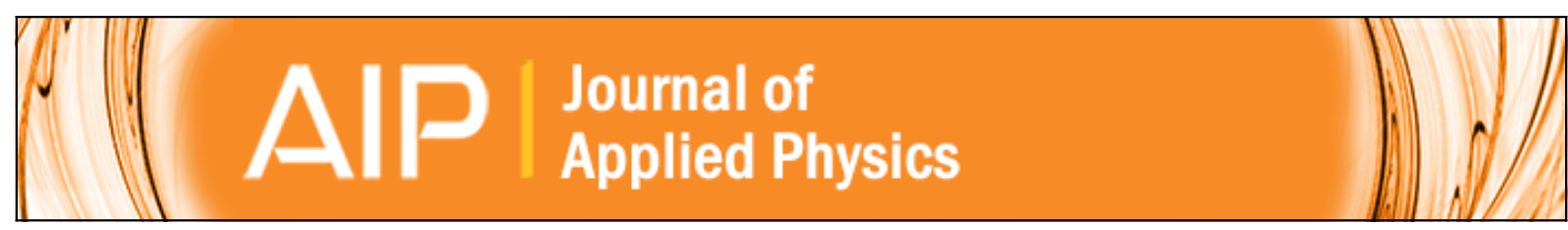

\section{Capacitance spectroscopy study of deep levels in $\mathrm{Cl}$-implanted $4 \mathrm{H}-\mathrm{SiC}$}

G. Alfieri and T. Kimoto

Citation: Journal of Applied Physics 112, 063717 (2012); doi: 10.1063/1.4754854

View online: http://dx.doi.org/10.1063/1.4754854

View Table of Contents: http://scitation.aip.org/content/aip/journal/jap/112/6?ver=pdfcov

Published by the AIP Publishing

\section{Articles you may be interested in}

Annealing behavior of the EB-centers and M-center in low-energy electron irradiated n-type $4 \mathrm{H}$-SiC

J. Appl. Phys. 109, 103703 (2011); 10.1063/1.3586042

Reduction of deep levels generated by ion implantation into $\mathrm{n}$ - and $\mathrm{p}$-type $4 \mathrm{H}-\mathrm{SiC}$

J. Appl. Phys. 108, 033706 (2010); 10.1063/1.3456159

Deep level transient spectroscopy study of defects in hydrogen implanted $\mathrm{p}$-type $4 \mathrm{H} \mathrm{Si} \mathrm{C}$

J. Appl. Phys. 101, 103716 (2007); 10.1063/1.2737630

Stability of deep centers in $4 \mathrm{H}-\mathrm{SiC}$ epitaxial layers during thermal annealing

Appl. Phys. Lett. 85, 1716 (2004); 10.1063/1.1790032

Deep-level transient spectroscopy study on double implanted $n+-p$ and $p+-n 4 \mathrm{H}-\mathrm{SiC}$ diodes

J. Appl. Phys. 95, 69 (2004); 10.1063/1.1623631

\section{AlP Re-register for Table of Content Alerts}




\title{
Capacitance spectroscopy study of deep levels in Cl-implanted $4 \mathrm{H}-\mathrm{SiC}$
}

\author{
G. Alfieri and T. Kimoto \\ Department of Electronic Science and Engineering, Kyoto University, Kyotodaigaku-katsura, Nishikyo, Kyoto \\ 615-8510, Japan
}

(Received 5 June 2012; accepted 29 August 2012; published online 27 September 2012)

\begin{abstract}
We report on a deep level transient spectroscopy study of $C l$-implanted $n$ - and $p$-type $4 \mathrm{H}-\mathrm{SiC}$ epilayers. Samples were electrically characterized after each step of an isochronal annealing series, between room temperature and $1800^{\circ} \mathrm{C}$, and twelve deep traps were detected. Of these, seven traps were found in $n$-type material, ranging from 0.15 to $1.6 \mathrm{eV}$ below the conduction band minimum $\left(E_{C}\right)$, and five were detected in $p$-type material, located between 0.5 and $1.7 \mathrm{eV}$ above the valence band maximum $\left(E_{V}\right)$. Besides the presence of the well known $Z_{1 / 2}$ and $E H_{6 / 7}$ levels in $n$-type $4 \mathrm{H}$-SiC and of the D-center in $p$-type samples, we found that $\mathrm{Cl}$ implantation gives rise to three new traps in $n$-type material at $E_{C}-0.37 \mathrm{eV}, E_{C}-1.06 \mathrm{eV}$, and $E_{C}-1.3 \mathrm{eV}$ and one new level in $p$-type at $E_{V}+0.97 \mathrm{eV}$. These traps are persistent after annealing at $1800^{\circ} \mathrm{C}$, and no data were found in the previous experimental studies reported in the literature. The possible involvement of $\mathrm{Cl}$ in the microscopic structure of these defects is discussed based on a depth profiling analysis of their concentration. (C) 2012 American Institute of Physics. [http://dx.doi.org/10.1063/1.4754854]
\end{abstract}

\section{INTRODUCTION}

Nowadays, one of the biggest challenges of the $\mathrm{SiC}$ industry is supplying affordable material of very high crystalline quality. Standard growth techniques, such as chemical vapor deposition (CVD), allow growth rates ranging between 5 and $10 \mu \mathrm{m} / \mathrm{h}$ which are time consuming and not economically viable because high-voltage devices rely on very thick epilayers $(\sim 100 \mu \mathrm{m})$. In order to overcome this problem, it was shown ${ }^{1-4}$ that the use of chlorinated precursors can effectively increase growth rates up to $170 \mu \mathrm{m} / \mathrm{h}$ (Ref. 5) yielding good quality epilayers, without stacking faults. ${ }^{6}$ Additionally, the increase of the flow rate results in the formation of Si droplets, ${ }^{1}$ which, if not flushed away from the growth chamber, will eventually come into contact with the crystal surface giving rise to defects in the epilayers. To the contrary, by introducing $\mathrm{Cl}$ in the reactor in the form of $\mathrm{HCl}, \mathrm{CH}_{x} \mathrm{Cl}_{y}, \mathrm{SiH}_{x} \mathrm{Cl}_{y}, \mathrm{Cl}$ can bind to $\mathrm{Si}$ and prevents the formation of the above mentioned droplets. This allows the increase of the flow rate resulting in an increase of the growth rates.

However, similarly to the case of $H$, which is present in the precursor gases and can be incorporated in $\mathrm{SiC}^{7}$ also $\mathrm{Cl}$ can be incorporated in $\mathrm{SiC}$ during growth. ${ }^{5,8}$ Even if the detected concentration is close to, or below, the detection limit $\left(\sim 10^{14} \mathrm{~cm}^{-3}\right),{ }^{5}$ the possibility that $\mathrm{Cl}$ atoms are incorporated in the $10^{11}-10^{12} \mathrm{~cm}^{-3}$ range cannot be excluded. This raises the question of whether or not $\mathrm{Cl}$ impurities give rise to electrically active defects, as is the case with $H$. The presence of electrically active levels in the band gap $\left(E_{G A P}\right)$ is a matter of extreme importance in device technology because they can act as charge carriers' traps and harm the correct functionality of devices. However, despite the importance of this topic, scarce experimental and theoretical information is present in the literature.

La Via et al. ${ }^{1}$ have shown by deep level transient spectroscopy (DLTS) that both the $Z_{1 / 2}$ and $E H_{6 / 7}$ levels are present in $n$-type $4 \mathrm{H}$-SiC grown by using $\mathrm{HCl}$ as a precursor and that new deep levels, related to $\mathrm{Cl}$, are not observed, at least in the $10^{13} \mathrm{~cm}^{-3}$ range. Subsequently, by employing density functional theory (DFT), it was found that $\mathrm{Cl}$ preferably occupies a $C$-site rather than a $S i$-site and behaves as a triple donor. ${ }^{9}$ Furthermore, $\mathrm{Cl}$ easily binds to $\mathrm{Al}$, giving rise to a very thermally stable complex defect, while it repels $N$ (which is a donor itself). ${ }^{10}$ The donor character of $\mathrm{Cl}$ and $\mathrm{Cl}$-related complexes ${ }^{10}$ can explain why the use of chlorinated precursors does not harm the net-donor concentration ${ }^{11}$ but cause the saturation of the net-acceptor concentration. ${ }^{12}$

In the following, we present a DLTS study on $\mathrm{Cl}$ implanted $n$ - or $p$-type $4 \mathrm{H}-\mathrm{SiC}$ epilayers, annealed in $100-$ $1800^{\circ} \mathrm{C}$ temperature range, in order to shed the light on the possible presence of $\mathrm{Cl}$-related electrically active defects in 4H-SiC.

\section{EXPERIMENTAL DETAILS}

We employed $n$ - or $p$-type $4 \mathrm{H}$-SiC epilayers doped with $N$ or $A l$, respectively $\left(N_{d} \approx N_{a}=7-8 \times 10^{15} \mathrm{~cm}^{-3}\right)$. Epilayers were implanted with $700 \mathrm{keV} \mathrm{Cl}$, which resulted in a mean projected range of $0.5 \mu \mathrm{m}$ from the surface ${ }^{13}$ and with a dose of $5 \times 10^{9} \mathrm{~cm}^{-2}$. Samples underwent an isochronal $(15 \mathrm{~min})$ annealing series in the $100-1800^{\circ} \mathrm{C}$ temperature range (annealing step of $100^{\circ} \mathrm{C}$ ) in an $\mathrm{Ar}$ atmosphere. Heat treatments below $1000{ }^{\circ} \mathrm{C}$ were carried out in a rapid thermal annealing furnace (RTA) while for higher temperatures, a chemical vapor deposition chamber was employed. A carbon cap was deposited on the epilayer surface for temperatures above $1100^{\circ} \mathrm{C}$ in order to minimize the effects of surface decomposition which was later removed by a dry oxidation process $\left(1 \mathrm{~h}\right.$ at $\left.800{ }^{\circ} \mathrm{C}\right) .{ }^{14}$

After each annealing step, samples were dipped in $H F$ for $10 \mathrm{~min}$, and $A u$ or $T i$ Schottky diodes were formed on the surface of $n$ - and $p$-type $4 \mathrm{H}-\mathrm{SiC}$ epilayers, respectively, by thermal evaporation. For $p$-type samples, ohmic contacts 
were formed on the backside of the as-grown samples, by depositing a $\mathrm{Ti} / \mathrm{Al} / \mathrm{Ni}$ tri-layer sintered for $10 \mathrm{~min}$ at $1000{ }^{\circ} \mathrm{C}$.

Electrical characterization was performed by capacitancevoltage $(\mathrm{C}-\mathrm{V})$ and Fourier-transform DLTS measurements. ${ }^{15}$ DLTS measurements were carried out in the $200-700 \mathrm{~K}$ temperature range, with a reverse bias of $\pm 6 \mathrm{~V}$ (in order to cover the whole implantation range), a filling pulse to $0 \mathrm{~V}$ for $1 \mathrm{~ms}$ and a period width of $0.2 \mathrm{~s}$. For annealing temperatures up to $400{ }^{\circ} \mathrm{C}$, the highest DLTS temperature limit coincided with the annealing temperature.

\section{RESULTS AND DISCUSSION}

In Figs. 1(a) and 1(b), the results of the $C-V$ measurements, for the as-grown and implanted $n$ - and $p$-type $4 \mathrm{H}-\mathrm{SiC}$ epilayers, are shown together with the implanted $\mathrm{Cl}$ and the total vacancies concentration profiles. The $C-V$ profiles are obtained by changing the reverse bias up to $6 \mathrm{~V}$ (depletion width at $0 \mathrm{~V} \sim 0.4 \mu \mathrm{m}$ ) while the implanted $\mathrm{Cl}$ and total vacancies profiles are obtained from full-cascade SRIM simulations, ${ }^{13}$ in which the threshold displacement energies were set to 20 and $35 \mathrm{eV}$ for $C$ and $S i$, respectively. For $n$-type (Fig. 1(a)), the net-donor concentration $\left(N_{d}\right)$ profile in the asimplanted sample is located well beyond the implanted zone, at a depth ranging between 0.8 and $1.3 \mu \mathrm{m}$. Subsequent heat treatments do not result in a significant donor reactivation closer to the implanted $C l$ profile. However, after annealing at $1400{ }^{\circ} \mathrm{C}$, the $N_{d}$ is reactivated at $\sim 0.6-0.7 \mu \mathrm{m}$ from the surface (shadowed area of Fig. 1(a)) where implanted $\mathrm{Cl}$ atoms are present in the $10^{12}-10^{14} \mathrm{~cm}^{-3}$ range. A similar behavior is observed in the $p$-type sample for which higher annealing temperatures $\left(1700^{\circ} \mathrm{C}\right)$ are needed for the net-acceptor concentration $\left(N_{a}\right)$ to be reactivated close to the $C l$ implanted profile. The lower concentration of $\mathrm{Cl}$, with respect to that of either $N_{d}$ or $N_{a}$, rules out the possibility that $C l$ itself may be responsible for the passivation of either $N$ or $A l$. Furthermore, in the $n$-type material, it would be difficult for $C l$ to bind to $N$ due to Coulombic repulsion. ${ }^{10}$ Instead, the absence of enhanced $N_{d}$ (or $N_{a}$ ) signal in the implanted region may be due to the presence of compensating centers generated

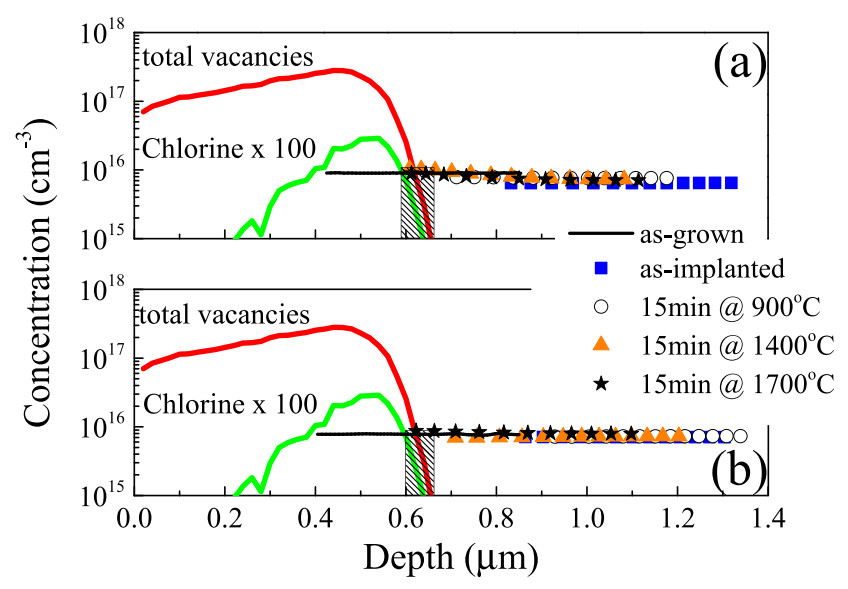

FIG. 1. Implanted $C l$ and total vacancies profiles plotted together with the (a) net-donor $\left(N_{d}\right)$ and (b) net-acceptor $\left(N_{a}\right)$ concentration, in the as-grown, as-implanted and 900,1400 , and $1700^{\circ} \mathrm{C}$ annealed epilayers. by implantation. As shown in Fig. 1, the total vacancy concentration is approximately $\sim 3 \times 10^{17} \mathrm{~cm}^{-3}$ and silicon vacancies $\left(V_{S i}\right)$ that are present in a negative (positive) charge state in the upper (lower) half of the band gap of $4 \mathrm{H}-\mathrm{SiC},{ }^{16-18}$ can be a cause for donor (acceptor) compensation. A similar analysis can be done for carbon vacancies $\left(V_{C}\right)$ which, contrarily to $V_{S i}$, have a higher thermal stability. ${ }^{19}$ In addition, the formation of doping related complexes, arising after implantation, cannot be excluded: For instance, after implantation, $N$ atoms can decorate $V_{S i}$ yielding $V_{S i}\left(N_{C}\right)_{x}$ (Ref. 20) which gives rise to an acceptor level in the upper half of the band gap and is thermally stable up to $2000{ }^{\circ} \mathrm{C}$, while $A l$ atoms can form $A l_{i} C_{i}$ which yields a donor level in the lower half of the band gap and has also a high thermal stability $\left(1700^{\circ} \mathrm{C}\right) .^{21}$

Fig. 2 shows the DLTS spectra obtained in as-grown material and after annealing at $700,1400,1800{ }^{\circ} \mathrm{C}$ for $n$ - and p-type $4 \mathrm{H}$-SiC. In as-grown $n$-type $4 \mathrm{H}$-SiC (Fig. 2 (a)), the $Z_{1 / 2}$ (concentration $2 \times 10^{13} \mathrm{~cm}^{-3}$ ) and $E H_{6 / 7}\left(12 \times 10^{13} \mathrm{~cm}^{-3}\right.$ ) are detected while, for $p$-type, we have found the $D$-center $\left(\sim 10^{12} \mathrm{~cm}^{-3}\right)$. After implantation (Fig. 2(b)), two levels are found in $n$-type $4 \mathrm{H}$-SiC: The broad DLTS peak at $400 \mathrm{~K}$ $\left(3 \times 10^{14} \mathrm{~cm}^{-3}\right)$ is identified as the $E H_{4}$ level $^{22}$ and a peak at $\sim 575 \mathrm{~K}\left(\sim 10^{15} \mathrm{~cm}^{-3}\right)$, at $1.34 \mathrm{eV}$ below the minimum of the conduction band $\left(E_{C}\right)$, and labelled $C i 1$ which has not been reported earlier in the literature. In $p$-type material, we found one level labeled $\mathrm{Ci} 2\left(2 \times 10^{12} \mathrm{~cm}^{-3}\right)$ at $0.51 \mathrm{eV}$ above the maximum of the valence band, $E_{V}$, and another one identified as the UK2 center $\left(2.5 \times 10^{12} \mathrm{~cm}^{-3}\right){ }^{23}$ Heat treatments at $1400{ }^{\circ} \mathrm{C}$ (Fig. 2(c)) results in the detection of the $Z_{1 / 2}(5$ $\left.\times 10^{14} \mathrm{~cm}^{-3}\right)$ and $E H_{6 / 7}\left(75 \times 10^{14} \mathrm{~cm}^{-3}\right)$ levels, for the $n$-type $4 \mathrm{H}-\mathrm{SiC}$ epilayer, while the $\mathrm{EH}_{4}$ is not detected at this annealing stage because it anneals out after $1200{ }^{\circ} \mathrm{C} .{ }^{24} \mathrm{We}$ note that the $\mathrm{EH}_{6 / 7}$ level may have been overlapping with the $\mathrm{Ci} 1$ level and becomes clearly visible only after the annealing of $\mathrm{Ci}$. For this reason, we considered the spectrum at $1400^{\circ} \mathrm{C}$ as the final annealing stage from which we subtracted the DLTS signal of the $700{ }^{\circ} \mathrm{C}$ annealed sample. The result of

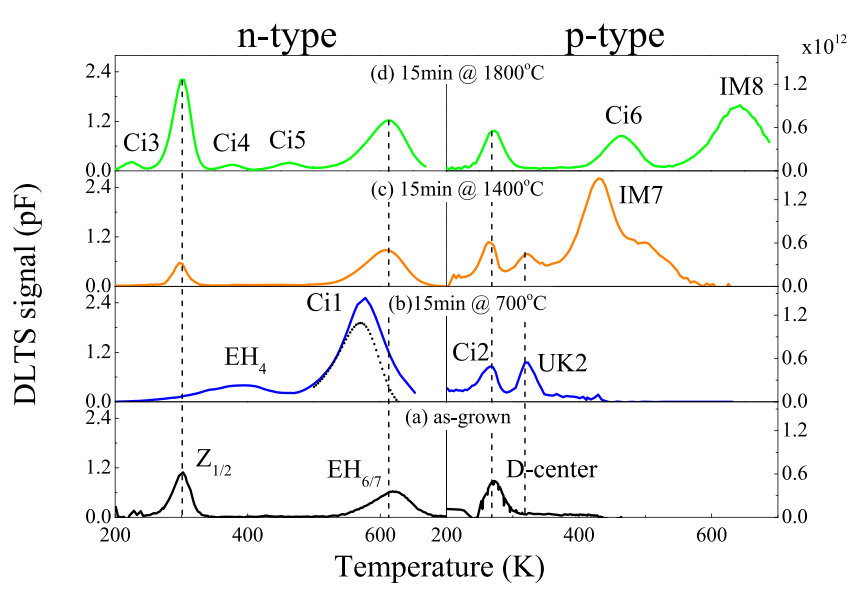

FIG. 2. DLTS spectra of the $n$ - and $p$-type $4 \mathrm{H}$-SiC epilayers annealed for $15 \mathrm{~min}$ at (a) as-grown, (b) $700^{\circ} \mathrm{C}$, (c) $1400^{\circ} \mathrm{C}$, and (d) $1800^{\circ} \mathrm{C}$. The signal of the DLTS spectra of the as-grown $n$-type material is multiplied by 100 . The black broken line represents the DLTS peak of the Ci1 level obtained from the subtraction of the spectrum detected after annealing at 700 and $1400{ }^{\circ} \mathrm{C}$ annealed $n$-type $4 \mathrm{H}$-SiC samples. 
the difference between the two DLTS spectra is shown by the broken line in Fig. 2(b) which may correspond to the real DLTS peak of the $C i 1$ level. For the $p$-type epilayer, the $C i 2$ and $U K 2$ levels are still present, and a new level is found at $\sim 430 \mathrm{~K}$ and identified as the IM7 level ${ }^{25}\left(\sim 10^{13} \mathrm{~cm}^{-3}\right)$. After the last annealing step $\left(1800{ }^{\circ} \mathrm{C}\right.$, Fig. $\left.2(\mathrm{~d})\right)$, the $Z_{1 / 2}$ and $E H_{6 / 7}$ are still detected in the $n$-type sample, and three new levels arise, labeled $\mathrm{Ci} 3, \mathrm{Ci} 4$, and $\mathrm{Ci} 5$ at $0.37 \mathrm{eV}\left(1.4 \times 10^{13} \mathrm{~cm}^{-3}\right)$, $1.06 \mathrm{eV}\left(2.4 \times 10^{13} \mathrm{~cm}^{-3}\right)$, and $1.3 \mathrm{eV}\left(3.4 \times 10^{13} \mathrm{~cm}^{-3}\right)$ below $E_{C}$, respectively. For $p$-type samples, while the $U K 2$ and IM7 are annealed out, the $C i 2$ is found to be persistent even after annealing at $1800{ }^{\circ} \mathrm{C}$ and at the same time two other levels arise: One is labeled $\mathrm{Ci} 6$ at $0.97 \mathrm{eV}\left(2.3 \times 10^{12} \mathrm{~cm}^{-3}\right)$ above $E_{V}$, and the other one is identified as the IM8 energy level $^{26}\left(8 \times 10^{12} \mathrm{~cm}^{-3}\right)$. A summary of the levels detected in the present study can be found in Table I.

Of all the levels, presently found in $n$-type $4 \mathrm{H}-\mathrm{SiC}$ epilayers, the $Z_{1 / 2}, E H_{6 / 7}$ and $E H_{4}$ have been reported earlier in a number of studies. It is well known that the $Z_{1 / 2}$ possesses a negative- $U$ behavior $^{27}$ and that its nature may be related to that of a carbon vacancy $\left(V_{C}\right) .^{28,29}$ The broad $E H_{6 / 7}$ is thought to be related to the $Z_{1 / 2}$ center: Both $Z_{1 / 2}$ and $E H_{6 / 7}$ are present in either the as-grown or irradiated/implanted material, share the same annealing behavior, ${ }^{29}$ and their concentration is reduced when carbon interstitials, $C_{i}$, are injected into the epilayer. ${ }^{30,31}$ The $E_{4}$ (Ref. 22) has been detected after irradiation with energetic particles or ion implantation, and it is believed to be related to a carbon cluster. ${ }^{24}$ Compared to the $Z_{1 / 2}$ and $E H_{6 / 7}$, the $E H_{4}$ has a lower thermal stability as it anneals out after heat treatments at $1200{ }^{\circ} \mathrm{C}$.

The trap labeled $\mathrm{Ci}$, found after $\mathrm{Cl}$-implantation, has an energy position close to that of the $E H_{5}$ (Ref. 22) and $E H_{6 / 7}^{*}$ (Ref. 32) levels, but it has a higher thermal stability. In addition, $\mathrm{Ci} 1$ was detected in concentrations as high as $10^{15} \mathrm{~cm}^{-3}$, higher than that of the implanted $\mathrm{Cl}\left(10^{14} \mathrm{~cm}^{-3}\right)$, and, for this reason, the possible involvement of $\mathrm{Cl}$ in its microscopic

TABLE I. Labeling, energy position in the band gap (with respect to $E_{C}$ or $E_{V}$, if the level is found in $n$ - or $p$-type $\mathrm{SiC}$, respectively) and capture cross section of all the detected levels found in the present study. The energy position and capture cross section are estimated from the Arrhenius plot of the emission time constant.

\begin{tabular}{|c|c|c|c|}
\hline Label & $\begin{array}{l}\text { Energy position } \\
\text { (eV) }\end{array}$ & $\sigma\left(\mathrm{cm}^{2}\right)$ & Comments \\
\hline$Z_{1 / 2}$ & $E_{C}-0.7$ & $3 \times 10^{-15}$ & Found after annealing at $1400^{\circ} \mathrm{C}$ \\
\hline $\mathrm{EH}_{4}$ & $E_{C}-1.03$ & $\sim 10^{-13}$ & Idem \\
\hline$E H_{6 / 7}$ & $E_{C}-1.6$ & $5 \times 10^{-13}$ & Idem \\
\hline$C i 1$ & $E_{C}-1.34$ & $1 \times 10^{-16}$ & Anneals at $1400^{\circ} \mathrm{C}$ \\
\hline $\mathrm{Ci3}$ & $E_{C}-0.37$ & $3 \times 10^{-16}$ & Stable up to $1800^{\circ} \mathrm{C}$ \\
\hline $\mathrm{Ci4}$ & $E_{C}-1.06$ & $3 \times 10^{-14}$ & Idem \\
\hline Ci5 & $E_{C}-1.3$ & $2 \times 10^{-13}$ & Idem \\
\hline $\mathrm{Ci2}$ & $E_{V}+0.51$ & $\sim 10^{-16}$ & Stable up to $1800^{\circ} \mathrm{C}$ \\
\hline$U K 2$ & $E_{V}+0.6$ & $\sim 10^{-16}$ & Anneals after $1400^{\circ} \mathrm{C}$ \\
\hline$I M 7$ & $E_{V}+0.79$ & $\sim 10^{-14}$ & Found after annealing at $1400^{\circ} \mathrm{C}$ \\
\hline Ci6 & $E_{V}+0.97$ & $8 \times 10^{-17}$ & Found after annealing at $1700^{\circ} \mathrm{C}$ \\
\hline$I M 8$ & $E_{V}+1.7$ & $8 \times 10^{-15}$ & Idem \\
\hline
\end{tabular}

structure can be ruled out. On the contrary, since the Ci1 level has similar temperature position and thermal stability (both levels anneal out below $1700{ }^{\circ} \mathrm{C}$ ) of those of the IN8 level found by Kawahara et al., ${ }^{33}$ we believe that $C i 1$ and IN8 levels may belong to the same defect. The $C i 3$ and $C i 4$ levels have a close energy position to that of the $P_{3}$ and $R D_{3}$ levels found in $\mathrm{He}^{+}$implanted 4H-SiC (Ref. 34), but since they have a different annealing behavior (both $P_{3}$ and $R D_{3}$ anneal out at $1400{ }^{\circ} \mathrm{C}$ ), they are more likely to have different origins. Analogously to the $\mathrm{Ci3}$ and $\mathrm{Ci4}$, also for the $\mathrm{Ci5}$ not much can be said on its microscopic nature. However, since these three levels have concentrations in the $10^{13} \mathrm{~cm}^{-3}$ range, the involvement of $\mathrm{Cl}$ in their microscopic structure may be more plausible. In fact, their detection coincides with the reactivation of $N_{d}$ at $0.6-0.7 \mu \mathrm{m}$ below the epilayer surface, and although neither theoretical nor experimental studies are present on $\mathrm{Cl}$ diffusion, the in-diffusion of $\mathrm{Cl}$ atoms at these temperatures cannot be excluded.

Much less is known on the nature of the traps detected in $p$-type $4 \mathrm{H}-\mathrm{SiC}$. The $U K 2, I M 7$, and $I M 8$ have all been reported earlier: The $U K 2$ was found in either electron irradiated $^{23}$ or hydrogen implanted ${ }^{25}$ material, while the IM7 and IM8 were detected in hydrogen implanted samples. $^{26}$ The $U K 2$ was associated to a carbon-related complex and the IM7 to an $A l$-related complex, while no hypothesis on the nature of the IM8 level has been put forward yet. The level labeled $\mathrm{Ci} 2$ was found in the asimplanted material, and for this reason, the participation of $C l$ in its microscopic structure can be ruled out. Instead, we consider the possibility that it may be identified with the $D$-center because they are both thermally stable up to $1800^{\circ} \mathrm{C}$, have similar energy position in the band gap, and the concentration of $\mathrm{Ci} 2$, in the as-implanted sample $\left(2 \times 10^{12} \mathrm{~cm}^{-3}\right)$, is very similar to that of the $D$-center found in as-grown samples. Regarding the Ci6 level, we exclude that this level could be identified with the IP6 level found in implanted $p$-type $4 \mathrm{H}-\mathrm{SiC},{ }^{33}$ because $\mathrm{Ci} 6$ has a higher thermal stability than IP6. To the contrary, similarly to $\mathrm{Ci3}, \mathrm{Ci}$, and $\mathrm{Ci5}$, the $\mathrm{Ci6}$ level arises when the $N_{a}$ is reactivated close to the implanted $C l$ profile. For the same reason, it can be thought that $C l$ can participate in the microscopic structure of Ci6.

In order to find out more evidence on the nature of the Ci2, Ci3, Ci4, Ci5, and Ci6 levels, we analyzed the depth profiles of these traps and compared them with the $\mathrm{Cl}$-implanted distribution obtained by Monte-Carlo simulations. ${ }^{13}$ These levels were detected in $n$ - and $p$-type samples that underwent the last annealing stage at $1800{ }^{\circ} \mathrm{C}$, and depth profiles measurements were performed by changing the reverse bias voltage up to $\pm 6 \mathrm{~V}$. As it is shown in Fig. 3, the concentration of the Ci2 trap is found outside the implanted region, at a depth of $0.65 \mu \mathrm{m}$ from the epilayer surface and has rather uniform depth distribution. The lack of a localized depth distribution close to the implanted $\mathrm{Cl}$ profile rules out the possible involvement of $\mathrm{Cl}$ in the microscopic nature of $\mathrm{Ci} 2$ and favors the identification of this defect as the $\mathrm{D}$-center. The depth profiles of $\mathrm{Ci3}, \mathrm{Ci} 4, \mathrm{Ci}$, and Ci6 display similar features: The concentrations of these traps show a rather steep increase of concentration for 


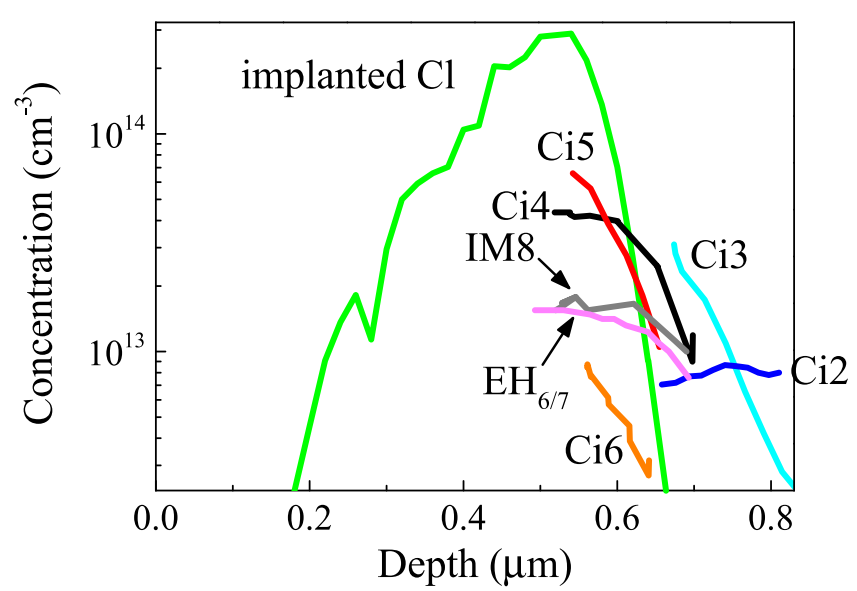

FIG. 3. Depth profiles of $\mathrm{Ci2}$, Ci3, Ci4, Ci5, and Ci6 levels found in either $n$ - or $p$-type $4 \mathrm{H}-\mathrm{SiC}$ epilayers implanted with $\mathrm{Cl}$ and annealed at $1800^{\circ} \mathrm{C}$. The depth profiles of two dominant traps found in $p$-type $4 \mathrm{H}-\mathrm{SiC}$ (IM8) and $n$-type $4 \mathrm{H}-\mathrm{SiC}\left(E H_{6 / 7}, Z_{1 / 2}\right.$ is not shown) are reported for comparison. The implanted $\mathrm{Cl}$ profile, as obtained by Monte-Carlo simulations, ${ }^{13}$ is also shown.

decreasing depth, in contrast to the more gradual increase of the $\mathrm{EH}_{6 / 7}$ and IM8 depth distributions. Analogously to $\mathrm{Ci}$, the depth profile of $\mathrm{Ci3}$ does not show a narrow and localized distribution close to the $C l$ implantation peak; therefore, also for this trap, it can be concluded that the involvement of $\mathrm{Cl}$ may be unlikely.

Regarding the Ci4, Ci5, and Ci6 levels two scenarios are possible. First, the extrapolation of these depth profiles, toward the surface, may yield very high defect concentration for a depth $\leq 0.6 \mu \mathrm{m}$. This rules out the possibility of $\mathrm{Cl}$ involvement but would explain why, even after heat treatments up to $1800^{\circ} \mathrm{C}$, no reactivation of either $N_{d}$ or $N_{a}$ has been achieved. Second, although the measurements are not feasible for a depth $\leq 0.6 \mu \mathrm{m}$, the depth profiles of $\mathrm{Ci}$, Ci5, and $\mathrm{Ci} 6$ may have a localized distribution around the maximum of the implantation peak, and for this reason, the involvement of $\mathrm{Cl}$ would be possible. If this would be the case, two different charge states of the $C l_{C} V_{S i}$ complex $^{10}$ are very close to the energy level position of $\mathrm{Ci} 4$ and $C i 5$ while a $C l$ interstitial $\left(C l_{i}\right)$ level was predicted at $E_{V}+0.96 \mathrm{eV},{ }^{9}$ very similar to the energy position of the Ci6 level.

\section{CONCLUSIONS}

Twelve deep levels were detected in either $n$ - or $p$-type $4 \mathrm{H}-\mathrm{SiC}$ implanted with $700 \mathrm{keV} \mathrm{Cl}$. Of these, four levels are found to arise after $\mathrm{Cl}$ implantation and labeled $\mathrm{Ci3}, \mathrm{Ci4}$, $C i 5$ (in $n$-type $4 \mathrm{H}-\mathrm{SiC}$ ), and $\mathrm{Ci6}$ (in $p$-type). The involvement of $\mathrm{Cl}$ in the microscopic nature of these defects was discussed in detail in the light of previous theoretical studies and of the results of a depth profile analysis. We conclude that the $\mathrm{Cl}$ involvement is unlikely for the $\mathrm{Ci3}$ level, whose nature could be linked to the presence of implantation related defects, but it may be more plausible for the $\mathrm{Ci4}, \mathrm{Ci5}$, and Ci6 levels.

\section{ACKNOWLEDGMENTS}

This work was supported by the Funding Program for World-Leading Innovative R\&D on Science and Technology (FIRST Program) and a Grant-in-Aid for Scientific Research (21226008) from the Japan Society for the Promotion of Science.

${ }^{1}$ F. La Via, G. Galvagno, G. Foti, M. Mauceri, S. Leone, G. Pistone, G. Abbondanza, A. Veneroni, M. Masi, G. L. Valente, and D. Crippa, Chem. Vap. Deposition 12, 509 (2006).

${ }^{2}$ F. La Via, G. Izzo, M. Camarda, G. Abbondanza, and D. Crippa, Mater. Sci. Forum 615-617, 55 (2009).

${ }^{3}$ F. La Via, S. Leone, M. Mauceri, G. Pistone, G. Condorelli, G. Abbondanza, F. Portuese, G. Galvagno, S. Di Franco, L. Calcagno, G. Foti, G. L. Valente, and D. Crippa, Mater. Sci. Forum 556-557, 157 (2007).

${ }^{4}$ H. Pedersen, S. Leone, A. Henry, F. C. Beyer, V. Darakchieva, and E. Janzén, J. Cryst. Growth 307, 334 (2007).

${ }^{5}$ H. Pedersen, S. Leone, A. Henry, V. Darakchieva, P. Carlsson, A. Gällström, and E. Janzén, Phys. Stat. Sol. (RRL) 2, 188 (2008).

${ }^{6}$ S. Leone, Y. C. Lin, F. C. Beyer, S. Andersson, H. Pedersen, O. Kordina, A. Henry, and E. Janzén, Mater. Sci. Forum 679-680, 59 (2011).

${ }^{7}$ N. Achtziger, J. Grillenberger, W. Witthuhn, M. K. Linnarsson, M. Janson, and B. G. Svensson, Appl. Phys. Lett. 73, 945 (1998).

${ }^{8}$ B. Reznik, D. Gerthsen, W. Zhang, and K. J. Hüttinger, J. Eur. Ceram. Soc. 23, 1499 (2003).

${ }^{9}$ G. Alfieri and T. Kimoto, J. Phys.: Condens. Matter 23, 415802 (2011).

${ }^{10} \mathrm{G}$. Alfieri and T. Kimoto, J. Appl. Phys. 111, 103705 (2012).

${ }^{11}$ H. Pedersen, F. C. Beyer, J. Hassan, A. Henry, and E. Janzén, J. Cryst. Growth 311, 1321 (2009).

${ }^{12}$ H. Pedersen, F. C. Beyer, A. Henry, and E. Janzén, J. Cryst. Growth 311, 3364 (2009).

${ }^{13}$ J. F. Ziegler et al., The Stopping and Range of Ions in Solids (Pergamon, New York, 1985).

${ }^{14}$ Y. Negoro, K. Katsumoto, T. Kimoto, and H. Matsunami, J. Appl. Phys. 96, 224 (2004).

${ }^{15}$ S. Weiss and R. Kassing, Solid-State Electron. 31, 1733 (1988).

${ }^{16}$ M. Bockstedte, A. Mattausch, and O. Pankratov, Phys. Rev. B 69, 235202 (2004).

${ }^{17}$ F. Bechstedt, A. Fissel, J. Furthmüller, U. Grossner, and A. Zywietz, J. Phys.: Condens. Matter 13, 9027 (2001).

${ }^{18}$ L. Torpo, T. E. M. Staab, and R. M. Nieminem, J. Phys.: Condens. Matter 13, 6203 (2001).

${ }^{19}$ Z. Zolnai, N. T. Son, C. Hallin, and E. Janzén, J. Appl. Phys. 96, 2406 (2004).

${ }^{20}$ U. Gerstmann, E. Rauls, Th. Frauenheim, and H. Overhof, Phys. Rev. B 67, 205202 (2003).

${ }^{21}$ A. Gali, T. Hornos, N. T. Son, E. Janzén, and W. J. Choyke, Phys. Rev. B 75, 045211 (2007).

${ }^{22}$ C. Hemmingsson, N. T. Son, O. Kordina, J. P. Bergman, and E. Janzén, J. Appl. Phys. 81, 6155 (1997).

${ }^{23}$ K. Danno and T. Kimoto, J. Appl. Phys. 101, 103704 (2007).

${ }^{24}$ G. Alfieri, E. V. Monakhov, B. G. Svensson, and M. K. Linnarsson, J. Appl. Phys. 98, 043518 (2005).

${ }^{25}$ G. Alfieri and T. Kimoto, Phys. Stat. Solidi B 246, 402 (2009).

${ }^{26}$ G. Alfieri and T. Kimoto, J. Appl. Phys. 101, 103716 (2007).

${ }^{27}$ C. Hemmingsson, N. T. Son, A. Ellison, J. Zhang, and E. Janzén, Phys. Rev. B 58, R10119 (1998).

${ }^{28}$ L. Storasta, J. P. Bergman, E. Janzén, A. Henry, and J. Lu, J. Appl. Phys. 96, 4909 (2004)

${ }^{29}$ K. Danno and T. Kimoto, J. Appl. Phys. 100, 113728 (2006).

${ }^{30}$ L. Storasta and H. Tsuchida, Appl. Phys. Lett. 90, 062116 (2007).

${ }^{31}$ T. Hiyoshi and T. Kimoto, Appl. Phys. Express 2, 091101 (2009).

${ }^{32}$ G. Alfieri, E. V. Monakhov, and B. G. Svensson, Mater. Sci. Forum 457-460, 481 (2004).

${ }^{33}$ K. Kawahara, G. Alfieri, and T. Kimoto, J. Appl. Phys. 106, 013719 (2009).

${ }^{34}$ T. Dalibor, G. Pensl, H. Matsunami, T. Kimoto, W. J. Choyke, A. Schöner, and N. Nordell, Phys. State Solidi A 162, 199 (1997). 